\title{
A NEGAÇÃO LÓGICA E A LÓGICA DO SUJEITO
}

Marta D'Agord

\author{
Doutora em \\ Psicologia; \\ professora do \\ Programa de Pós- \\ Graduação em \\ Psicologia Social e \\ Institucional e do \\ Departamento de \\ Psicanálise e \\ Psicopatologia do \\ Instituto de \\ Psicologia, UFRGS; \\ membro do GT \\ Pesquisa em \\ Psicanálise da \\ Anpepp e da \\ Associação \\ Universitária de \\ Pesquisa em \\ Psicopatologia \\ Fundamental.
}

RESUMO: Apresenta-se um estudo sobre a produtividade do conceito de negação para a teoria psicanalítica. Se em Freud observamos que a Lógica exerce um importante papel comparativo, em Lacan, a Lógica oferece instrumentos para pensar o sujeito do inconsciente. O trabalho toma como ponto de partida duas acepções de negação, a negação dos contrários e a negação dos contraditórios. Essas duas acepções são analisadas nos campos da lógica e da psicanálise. A partir da análise lacaniana do conceito de negação em Lógica e em Freud, mostra-se como Lacan produz uma lógica do sujeito do inconsciente a partir da lógica moderna.

Palavras-chave: Psicanálise, lógica, negação.

ABSTRACT: The logic negation and the logic of the subject. This article presents a study on the productivity of the concept of negation for the psychoanalytical theory. If in Freudian works, we observe that the Logic exerts an important comparative paper, in Lacanian field, the Logic offers instruments to think the subject of the unconscious. The work takes, as starting point, two negation meanings, the negation of the contrary and the negation of the contradictory. These two meanings are analyzed in the logic and psychoanalytical fields. The article presents the Lacanian analysis of the Freudian concept of negation and the Logic concept of negation. The study reveals as Lacan produces a logic of the subject of the unconscious based on the modern logic.

Keywords: Psychoanalysis, logic, negation.

E ste artigo apresenta uma pesquisa sobre a produtividade da negação lógica para a teoria psicanalítica. A negação é um tema fundamental na Filosofia, desde seus primórdios, com os pré-socráticos Parmênides de Eléia (c. 530-460 a.C.) e Heráclito. Contrariando Heráclito, que usava a imagem de um 
rio para sustentar que é possível a uma coisa ser e não ser, Parmênides dizia: “Ou totalmente é necessário ser ou não”. Essa idéia tornou-se regra quando Aristóteles observou que "nunca se deve asseverar que o mesmo é e não é” (ARISTÓTELES, Metafísica, IV, 6, p.12). É com Aristóteles, portanto, que esse aforismo se transforma em um dos princípios da lógica. Este princípio é conhecido como princípio de contradição (também chamado de princípio de não-contradição), e diz o seguinte: “algo não pode, ao mesmo tempo, ser e não ser o caso”. Os outros dois princípios são o princípio de identidade (A é A) e o princípio do terceiro excluído (p ou não-p).

Freud e Lacan não desconheciam a Lógica, pelo contrário, sempre buscaram neste campo uma fonte de recursos metodológicos e uma fonte de comparação com seus achados. É possível observar, no texto da Verneinung ${ }^{1}$ (FREUD, 1925), que a Lógica exerce um importante papel comparativo para a metapsicologia freudiana. É o caso quando Freud mostra seu conhecimento quanto à diferença entre juízos de atribuição e juízos de existência.

“A função do julgamento está relacionada, em geral, com duas espécies de decisões. Ele afirma ou desafirma a posse, em uma coisa, de um atributo particular, e assevera ou discute que uma representação tenha uma existência na realidade."2 (FREUD, 1925 / 1987, p.297)

A que se refere Freud senão à divisão entre proposições categóricas universais e existenciais? Asseverar a posse de um atributo equivale a uma proposição universal, asseverar a existência equivale a uma proposição existencial. No texto da Verneinung, Freud (1925) a compara à negação lógica.

Já, para Lacan, a Lógica oferece instrumentos para pensar o sujeito do inconsciente no discurso. Se Lacan pôde aproveitar o que a Lógica oferecia como recurso metodológico, é porque, uma geração após Freud, os desenvolvimentos mais recentes da Lógica, aqueles produzidos desde Frege, já estavam acessíveis.

A Lógica tradicional estruturava os silogismos a partir da diferenciação entre tipos de juízos: os juízos singulares (Sócrates é um homem), os juízos universais (Todo homem é mortal) e os juízos particulares (Alguns homens são mortais). Na concepção tradicional, todas as frases enunciativas simples eram predicativas,

\footnotetext{
${ }^{1} \mathrm{O}$ termo alemão Verneinung foi traduzido como negativa, mas, desde a análise de Hyppolite, vem sendo traduzido por denegação. Em Lógica, o termo poderia ser traduzido por negação, e a tradução inglesa optou por negation. Utilizaremos a expressão negação, reservando as traduções denegação e negativa quando se tratar da análise de Hyppolite sobre a atitude de negação.

2 "Die Urteilsfunktion hat im wesentlichen zwei Entscheidungen zu treffen. Sie soll einem Ding eine Eigenschaft zu- oder absprechen, und sie soll einer Vorstellung die Existenz in der Realität zugestehen oder bestreiten" (FREUD, Studiensausgabe, Bd. III, 1925/1972, p.374).
} 
isto é, compostas de sujeito e predicado. O predicado está sempre no lugar de um conceito ou de uma classe. E, com a frase predicativa, se dizia que algo (o sujeito) caía sob um conceito ou uma classe. Assim, em um juízo, ligava-se um sujeito a um predicado.

Devido a essa exigência de ligação entre sujeito e predicado em um processo inferencial, a silogística exigia a presença de um termo médio, contido em ambas as premissas, no lugar do sujeito ou do predicado. A lógica moderna admitiu que se trabalhasse não apenas com juízos, mas também com frases enunciativas. Para isso, foi importante a contribuição de Frege (1848-1925), com o Begriffschrift (1879), no qual ele propôs que a terminologia 'sujeito e predicado' fosse substituída pela distinção de formas proposicionais de acordo com a teoria das funções. Surgia a Lógica moderna, na qual uma proposição é formada por uma expressão relacional, isto é, uma função, e um par ordenado de expressões-sujeito. Por exemplo: no enunciado "João é pai de Pedro”, há a expressão relacional "é o pai de" e o par ordenado \{João, Pedro\}. Isso significa que existe, entre os dois objetos, João e Pedro, a relação “ser pai de” (TUGENDHAT e WOLF, 1997, p.65-67; KNEALE e KNEALE, 1962, p.442-449).

É Frege (1918-1919/2002), também, quem propõe uma nova concepção de negação lógica, ao mostrar que uma negação não equivale a um pensamento, mas se exerce de modo formal. Ele mostra que, se a negação não dá existência ou tira a existência de nada, ela deve ser concebida como discursiva. É ao tema da contradição a que Frege chega, como forma última de mostrar o funcionamento da negação no discurso: dados dois pensamentos, A e a negação de A, sempre existe um, e somente um, que é verdadeiro. É, portanto, somente através do funcionamento discursivo oferecido pela negação (através da contradição) que seria possível atingir a verdade lógica (validade).

Se a linguagem, para a Lógica, está relacionada ao controle sobre as proposições, para a psicanálise, ela supõe a escuta do sujeito do inconsciente para além dos atos de fala, isto é, em referência ao campo da linguagem, ao tesouro de significantes da língua do falante. É na fala que é possível encontrar hesitações, esquecimentos e negações. Logo, se o campo da linguagem está concernido quando Lógica e Psicanálise se ocupam da negação, vale lembrar que as acepções e métodos são distintos.

Na obra freudiana, o conceito de negação é encontrado em duas acepções. A primeira delas diz respeito ao não dos contrários e dos opostos, como aparece em $A$ interpretação dos sonhos (1900) e no artigo “A significação antitética das palavras primitivas” (1910), inspirado nas pesquisas do filólogo Abel.

A segunda acepção de negação aparece no artigo sobre a Verneinung (1925). Nessa segunda acepção, a negação consta como constitutiva do que é negado. Freud (1925) compara a fala e a forma lógica da negação: esta envolve uma 
acepção de verdade proposicional, aquela envolve um desejo recalcado que é reconhecido, mas não admitido.

\section{A NEGAÇÃO COMO CONTRÁRIO}

A primeira negação da qual a teoria psicanalítica se ocupa é a concepção de negação enquanto contrário ou oposto. A consideração aos contrários aparece em $A$ interpretação dos sonhos. Freud (1900) sustenta que os sonhos são a realização do desejo. Isso é regra, mesmo que a figuração do sonho seja contrária ao desejo. Por isso, quando, em um sonho, aparece uma negação ou oposição à realização de algum desejo, "não há maneira de decidir, num primeiro relance, se determinado elemento que se apresenta por seu contrário, está presente nos pensamentos do sonho como positivo ou negativo" (FREUD, 1900/1990, p.324).

Um sonho que ilustra esse processo de figurar o contrário é narrado a Freud por uma paciente, que aproveita para questionar a hipótese de que os sonhos são a realização do desejo. Nesse sonho, a paciente não conseguia encontrar salmão defumado para oferecer a uma amiga no jantar. Das associações da paciente, sabe-se que, no dia anterior, a amiga manifestara o desejo de jantar na casa da paciente. A paciente ainda comenta que pedira a seu marido que não lhe fornecesse caviar (ele era açougueiro), embora desejasse comer caviar diariamente. No sonho, a amiga ficava sem o salmão, assim como a paciente, na vida de vigília, ficava sem o caviar. Na interpretação de Freud, o desejo realizado em sonho é a identificação da paciente com a amiga (FREUD, 1900/1990, p.164167). Trata-se de uma forma de identificação chamada por Freud de 'identificação histérica' e, como é possível observar a seguir, não é um problema sem relações com a questão da linguagem. Nas Minutas da Sociedade Psicanalítica de Viena, encontramos a seguinte observação de Freud: “A tendência a mentir das histéricas lembra o velho paradoxo dos cretenses (Epimênides): quando uma histérica afirma haver mentido, é justamente essa afirmação que pode ser uma mentira". 3

Benveniste (1995) observa que os contrários não são privilégio exclusivo das formas primitivas da língua, como o trabalho de Abel teria sugerido a Freud, mas fazem parte da linguagem, especificamente, no mito e na poesia surrealista. Essa última aparenta-se ao sonho ao sugerir o mesmo modo de estruturação, introduzindo, nas formas normais da linguagem, essa indeterminação do sentido projetada em sonho.

\footnotetext{
3 "La tendance à mentir des hystériques rappelle le vieux paradoxe des Cretois [Épiménides]: quand une hystérique prétend avoir menti, c'est justement cette affirmation qui peut éter un mensonge” (NUNBERG, H. e FEDERN, E., 1979, p.36).
} 


\section{CONTRÁRIOS NÃO SÃO CONTRADITÓRIOS}

Em Lógica, a relação entre os contrários faz parte das leis de inferência formuladas por Aristóteles. Essas podem ser visualizadas por meio do que se convencionou chamar de Quadrado Lógico, conforme figura a seguir:

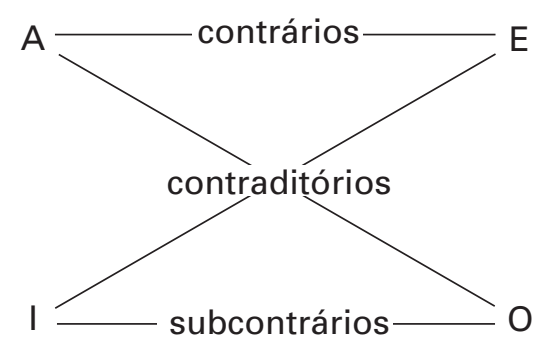

Aristóteles, no tratado Da Interpretação definira, como contradição, a oposição entre uma afirmação que expressa um sujeito universal (tomado universalmente) e uma negação que exprime o mesmo sujeito não tomado universalmente. Aristóteles trabalha com o seguinte exemplo: "Todo homem é branco" opõe-se, contraditoriamente, a "Algum homem não é branco". A partir dessa definição, a tradição distinguiu quatro constantes que formam o clássico quadrado lógico: A, E, I, O, que são:

A: a universal afirmativa: "Todo homem é branco".

E: a universal negativa: "Nenhum homem é branco".

I: a particular positiva: "Algum homem é branco".

O: a particular negativa: "Algum homem não é branco".

Duas proposições são contrárias quando, do que é universal, se afirma, de maneira universal, que é ou se nega que é. Assim, uma oposição entre contrários é aquela que existe entre proposições universais afirmativas, por exemplo "Todo homem é branco" e as universais negativas, por exemplo, "Nenhum homem é branco" (ARISTÓTELES, Periermeneias, VII, p.130).

A regra de inferência para se obter o valor de verdade de uma das proposições contrárias, dado que se tenha o valor de verdade da outra, é a seguinte: Se um contrário é verdadeiro, o outro é sempre falso. Mas, se um contrário é falso, não se segue que o outro seja verdadeiro, ou seja, podem ser ambos falsos. Se a proposição "Todos os homens são mortais" é falsa, não se segue que "Nenhum homem é mortal" seja verdadeira, ou seja, essa última pode também ser falsa. Como explica Cirne-Lima (1997), "Se a gente sabe que um dos contrários é falso, não dá para concluir nada sobre o contrário oposto” (CIRNE-LIMA, 1997, 
p.103). Em Lógica, portanto, os contrários podem se excluir mutuamente ou não. Não é o caso dos contraditórios, que, necessariamente, excluem um ao outro.

\section{A NEGATIVA COMO CONSTITUTIVA DO QUE É NEGADO}

O texto freudiano sobre a Verneinung introduz uma outra forma de não, um não que supõe uma afirmação. Neste caso, a negativa seria uma forma de tomar conhecimento do recalcado, como que uma suspensão (Aufhebung) do recalque, mas sem aceitação (Annahme) do que foi recalcado. Há, portanto, reconhecimento do inconsciente pelo eu, mas esse reconhecimento se expressa em forma negativa. ${ }^{4}$ Eis a dimensão de reconhecimento (Anerkennung): no movimento de suspensão do recalque, o eu não admite o inconscientizado, mas o reconhece, justamente, nesse ato de não-admissão.

No "Comentário falado sobre a Verneinung de Freud”, Hyppolite (1989) faz a distinção entre a negação lógica e a atitude de negação, que seria "a Verneinung enquanto atitude fundamental de simbolicidade explicitada” (HYPPOLITE, 1989, p.55).

A negativa enquanto Verneinung e a negação lógica seriam, portanto, duas diferentes formas de negação. A negação lógica é a negação de uma afirmação (Behauptung), enquanto que a negativa da Verneinung supõe uma acolhida (Bejahung) primordial. Na interpretação de Hyppolite, a negação lógica e a negativa (denegação) própria à Verneinung dizem "não” de forma diferente. A denegação não é o "não” da lógica formal, mas o símbolo desse “não” por meio da enunciação, sendo, pois, o desmentido que se acolheu: desmentindo uma enunciação, mostra-se que ela foi acolhida. Enquanto que a negação lógica se relaciona ao princípio da contradição, isto é, não é possível que algo seja e não seja ao mesmo tempo e sob as mesmas circunstâncias, a negação psicanalítica relaciona-se ao primeiro acolhimento (Bejahung).

Ambas as formas de negação não se excluem, pois estão situadas em campos diferentes. Na Verneinung, trata-se da relação entre o retorno do recalcado e a admissão ou destituição do seu conteúdo. Da interpretação de Hyppolite, Lacan toma o fio condutor que lhe permite mostrar em que sentido o recalque é diferente da Verwerfung. Se no recalque algo pode ser desconhecido pelo sujeito após ter sido verbalizado, então é preciso admitir, atrás do processo de verbalização, uma acolhida (Bejahung) primordial, uma admissão no sentido simbólico, que, mesmo contestada, é reconhecida nessa contestação. Caso falte essa admissão simbólica, a negação não ocorre sob a forma do recalque (Verdrängung), mas da

\footnotetext{
4 "Zu dieser Auffasung der Verneinung stimmt es sehr gut, dass man in der analyse kein "Nein" aus dem Unbewussten auffindet und dass die Annerkennung des Unbewussten von seiten des Ichs sich in einer negativen Formel ausdrückt" (FREUD, 1925/1975, p.377).
} 
exclusão ou repúdio (Verwerfung). Pode acontecer que um sujeito recuse o acesso, ao seu mundo simbólico, de alguma coisa que, no entanto, ele experimentou e que não é outra coisa, naquela circunstância, senão a ameaça da castração. Lacan mostra que Freud já fazia essa distinção quando escrevia sobre a Verwerfung do caso do "Homem dos lobos": "O sujeito nada quer saber disso no sentido do recalcado” (LACAN, 1955-1956/1985, p.21). O conceito de uma Bejahung primordial revela, segundo Lacan, que, na origem, para que o recalque seja possível, é preciso "um primeiro núcleo do recalcado, como centro de atração que chama para si todos os recalques ulteriores” (LACAN, 1953-1954/1979, p.56).

Essa idéia de uma acolhida que sofre um primeiro recalque vai ao encontro da negação própria ao campo da Linguagem. Benveniste (1995) mostra que a acepção de negação na Verneinung é uma acepção lingüística:

\footnotetext{
“A característica da negação lingüística consiste em que ela pode anular apenas o que é enunciado, que deve apresentá-lo explicitamente para suprimi-lo, e que um julgamento de não-existência tem necessariamente também o status formal de um julgamento de existência." (BENVENISTE, 1995, p.91)
}

Para Benveniste (1995), o fator lingüístico é decisivo na Verneinung de Freud, pois a negação é constitutiva do conteúdo negado, de forma que o sujeito não tem mais poder sobre a existência desse conteúdo. Ou seja, o conteúdo existe, mesmo que não admitido pelo sujeito. O discurso do sujeito pode contestar o conteúdo, mas não abolir a propriedade fundamental da linguagem, que consiste em implicar que 'algo' corresponde àquilo que se enuncia — algo e não nada.

Benveniste, assim como Hyppolite, supõe a distinção entre a Verneinung, a qual pertence ao campo da enunciação, e a negação lógica pertencendo ao campo da proposição. Na primeira, está em questão a verdade do sujeito, na segunda, está em questão a validade lógica de uma proposição. Se a Verneinung de Freud é correlativa de uma verdade que foi verbalizada, mas não admitida, estaria, portanto, suposta uma divisão entre um sujeito da enunciação e um sujeito do enunciado. Um conteúdo é verbalizado, isto é, simbolicamente reconhecido, mas não admitido como existente para o eu. A frase freudiana é clara: "Negar algo em um julgamento é, no fundo, dizer: 'Isto é algo que eu preferiria reprimir'."5

Lacan analisa a Verneinung a partir da relação com o outro e com o Outro. Em um primeiro momento, apresenta a relação com o outro, relacionada à especularidade e, portanto, como constitutiva do eu. É preciso considerar a Verneinung, afirma Lacan (1946/1998), como:

\footnotetext{
5 "Etwas im Urteil verneinen, heisst im Gründe: 'Das ist etwas, was ich am liebsten verdrängen möchte" (FREUD, 1925/1975, p.374).
} 
"Uma negação formal: em outras palavras, de um fenômeno típico de desconhecimento (méconaissance) e sob a forma invertida (inversée) (...) forma cuja expressão mais habitual — Não vá pensar que... - já nos fornece essa relação profunda com o outro como tal, que valorizaremos no Eu (Moi).” (LACAN, 1946/1998, p.181)

Assim, se o que é submetido à Verneinung supõe um outro em relação ao Eu, é porque, antes disso, há um Outro, há um acolhimento simbólico, uma Bejahung primordial que permite esse movimento da Verneinung. Assim, o que foi submetido à Bejahung, mesmo recalcado, persiste, retorna na repetição (retorno do recalcado), é submetido ao movimento da denegação, é uma presença simbólica. É nesse sentido que Lacan se refere à presença do significante no Outro como uma presença vedada ao sujeito na maioria das vezes. É vedada, mas acolhida, pois foi submetida ao recalque originário (Urverdrängung).

A Psicanálise, já com Freud, admite a hipótese da divisão entre sujeito do enunciado e sujeito da enunciação. Ou seja, a Psicanálise reconhece essa divisão, ou melhor, o próprio eu reconhece essa divisão a cada vez que nega o que acabou de verbalizar.

E na Lógica, como é abordada essa hipótese de uma divisão entre sujeito da enunciação e sujeito do enunciado?

\section{A CONTRADIÇÃO LÓGICA}

No campo da Lógica, trabalha-se com proposições suscetíveis de serem submetidas à crítica, isto é, que ofereçam referência às condições necessárias para que, de uma proposição, se possa deduzir outra. Assim, a proposição lógica está limitada por condições formais, isto é, necessárias. A primeira dessas condições é, justamente, a valorização da função da negação, que aparece tanto no princípio de contradição como no princípio do terceiro excluído.

O princípio da contradição (também chamado de princípio de não-contradição) afirma que "Nenhuma proposição pode ser verdadeira e falsa".

O princípio do terceiro excluído afirma que uma proposição ou é verdadeira ou é falsa; assim, dada uma proposição p, tem-se ou p ou não-p.

A função desses princípios é o controle da validade das proposições através de tabelas de verdade. Esse controle é o exame da validade de uma seqüência de proposições para a formação de um argumento, por exemplo.

Lacan (1961-1962/2003), no Seminário A identificação, analisa a relação entre a função da negação e o universal aristotélico do quadrado das oposições. Ao trabalhar com os conceitos aristotélicos, Lacan se apóia na interpretação do universal como o que tem seu lugar no processo de um discurso. A afirmação universal "todo o traço é vertical” é perfeitamente compatível com o fato de que não exista traço algum. Esse enunciado de discurso, que é a universal afir- 
mativa, não implica que haja, para lhe corresponder na realidade, o menor conjunto de traços.

Mas, pergunta Lacan, o universal ao qual se refere a proposição universal afirmativa, depende do ser ou do discurso? Para responder a essa questão, Lacan se reporta à crítica que Peirce (1839-1914) fez às classificações lógicas de Aristóteles. É possível, então, mostrar que a distinção universal-particular e a oposição afirmativa-negativa não são da mesma ordem. Para acompanhar o processo que leva Lacan a essa conclusão, vamos destacar os três momentos da análise realizada por Cathelineau (1998).

O primeiro momento consiste em uma apresentação do quadrante de Peirce. Tradicionalmente, entendia-se que as proposições afirmativas envolviam a existência de seus sujeitos, enquanto que as proposições negativas não. Peirce (1968) vai mostrar que as proposições particulares envolvem a existência de seus sujeitos, mas as universais não. Peirce cria uma figura de quatro quadrantes para ilustrar os quatro tipos de proposições. Dada a figura utilizada por Peirce (1968, p.96):

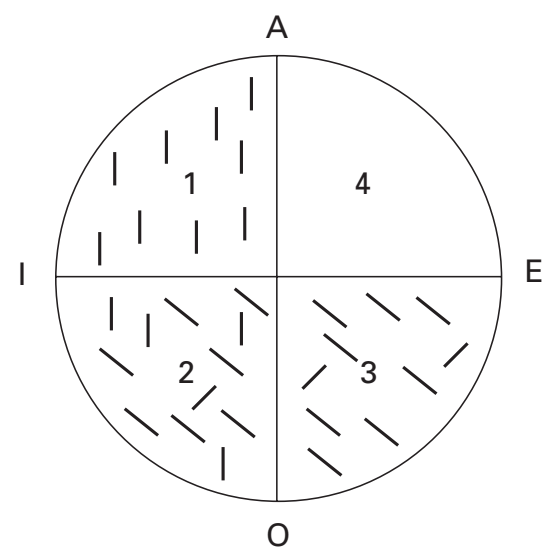

No quadrante 1, todos os traços são verticais; no quadrante 2, alguns são verticais e outros não; no quadrante 3 , nenhum dos traços é vertical; no quadrante 4 , não há traço algum.

Tipo A: Universal afirmativa: Todo traço é vertical.

Tipo E: Universal negativa: Nenhum traço é vertical.

Tipo I: Particular afirmativa: Algum traço é vertical.

Tipo O: Particular negativa: Algum traço não é vertical.

Aplicando os quatro tipos de proposições aos quatro quadrantes temos: 
A proposição A é válida quanto aos quadrantes 1 e 4 e inválida quanto aos quadrantes 2 e 3.

A proposição E é válida quanto aos quadrantes 3 e 4 e inválida quanto aos quadrantes 1 e 2 .

A proposição I é válida quanto aos quadrantes 1 e 2 e inválida quanto aos quadrantes 3 e 4 .

A proposição O é válida quanto aos quadrantes 2 e 3 e inválida quanto aos quadrantes 1 e 4 .

De onde se deduz, afirma Peirce (1968), "que A e O se negam entre si, assim como E e I” (1968, p.97).

A proposição de tipo A “todo o traço é vertical” refere-se ao que é universal, ao que está escrito, isto é, à dimensão do juízo de atribuição, mas não envolve um juízo de existência. Enquanto que a proposição de tipo O, “Ao menos um não é vertical” é um juízo de existência.

No quadrante superior direito, há o acolhimento do traço, mesmo que seja pela sua ausência (não há nenhum traço no quadrante direito). Dessa forma, a universal afirmativa e a universal negativa se encontram em razão do setor vazio, ou seja, não são contraditórias, mas contrárias. Por outro lado, somente pela existência de um que não é traço vertical, há também uma forma de acolhimento, confirma-se que o traço existe, porque há um que não é vertical.

A universal afirmativa reuniu os dois setores do alto: um setor cheio de traços verticais e um setor vazio. A universal negativa comporta também um setor em que "algum traço não é vertical” — são os traço oblíquos — e um setor vazio. Contrariamente à lógica aristotélica, que separa nitidamente universal afirmativa e universal negativa, o desenho de Peirce mostra que duas proposições que não podem ser verdadeiras ao mesmo tempo têm uma intersecção: o setor vazio. O desenho de Peirce confirma, pois, a idéia de que é verdadeiro dizer que "todo traço é vertical”, mesmo que não exista nenhum traço particular. A proposição universal não remete a coisas existentes; ela é "puro enunciado de discurso" (tradução livre) (CATHELINEAU, 1998, p.264). Esse puro enunciado de discurso funda-se sobre si mesmo.

Em um segundo momento, Lacan apóia-se sobre o estatuto da classificação em A, E, I, O. Esse estatuto repousa, de fato, na combinação de dois pares distintos que a lógica contemporânea, com Frege, ensina a distinguir: de um lado, a distinção universal-particular, e, de outro, a oposição afirmativa-negativa. Para Lacan, A se opõe também duplamente a O; E se opõe duplamente a I. A oposição universal-particular é da ordem da $\lambda \varepsilon \xi_{l} \zeta$. Esse substantivo grego provém do verbo $\lambda \varepsilon \gamma \omega$, “eu leio”, “eu escolho”, relacionado à função de escolha do signifi- 
cante. A $\lambda \varepsilon \xi_{l} \zeta$ distingue-se da $\varphi \alpha \sigma l \zeta$. Esta corresponde à fala pela qual alguém se engaja quanto à existência do que se apresenta como $\lambda \varepsilon \xi i \zeta$. Assim, a proposição “Todo homem é branco" depende de uma proposição que pode ser lida por aquele que a enuncia, sem dizer se ele a afirma ou a nega. O enunciado testemunha, pois, a escolha de combinar tal operador lógico — Todo — com tal significante ou tal letra - homem e mortal. Em um segundo tempo, o sujeito se engaja para afirmar ou negar o enunciado em questão. A oposição afirmativanegativa é, pois, da ordem de um “dizer” $(\varphi \alpha \sigma \imath \zeta)$, da palavra de um sujeito (tradução livre) (CATHELINEAU, 1998, p.265).

No terceiro momento, Lacan analisa a incidência do ato de enunciação sobre a formulação da universal afirmativa, em suas relações com a particular negativa. Como observa Cathelineau (1998), a universal afirmativa é um enunciado que afirma o sujeito do inconsciente, trata-se, portanto, da lógica do inconsciente. O que Lacan quer mostrar, afirma Cathelineau (idem), é que o quadrante de Peirce nos constrange a fundar o universal não mais sobre ele mesmo, como parecia ser o caso na lógica de Aristóteles, mas sobre a exceção que vai introduzi-lo (tradução livre) (CATHELINEAU, 1998, p.266).

Para enunciar a universal afirmativa, isto é, enunciar isso que é representado pelo setor de traços verticais e pelo setor vazio — no alto — seria mais preciso dizer: "Nada de traço que não seja vertical". Com efeito, "Todo traço é vertical" não diz nada do traço ao qual, entretanto, no esquema, o traço vertical se opõe: o traço oblíquo, que, ele também, é um traço. Pelo rigor, seria preciso isolar a existência de um traço, o traço vertical, e, num segundo tempo, negar que a classe dos traços que se quer caracterizar possa ser outra coisa que a classe dos traços verticais. Chega-se à enunciação: "Nada de traços que não sejam verticais". Na universal afirmativa, o sujeito é convocado duas vezes: ele destaca um traço, um traço particular que faz, aqui, figura de exceção, e ele nega que, em relação ao segmento que contém esse traço, os outros segmentos possam ser pertinentes. É assim que, para Cathelineau (1998),

\footnotetext{
"Fundando a lógica sobre a dimensão declarativa do discurso, Lacan descobre que a classe dos traços verticais não é a coleção, o interior da classe maior dos traços em geral, de todos os traços traçados no sentido vertical, mas aquilo que excluímos dos outros traços pela colocação em função do traço vertical." (CATHELINEAU, 1998, p.266, tradução livre).
}

Lacan determina-se a mostrar que a lógica do discurso declarativo, aquele da afirmação e da negação que, em última instância, isola o traço distintivo, conduz a uma outra lógica, da qual Aristóteles esboça as primeiras questões. Com isso, quando nego que haja, numa classe, um traço que não seja vertical, constituo a 
classe dos traços verticais, e, assim, para todas as universais afirmativas que eu propuser. Só posso afirmar um universal se eu excluir, previamente, um traço de todos os outros traços que servirá para caracterizar o universal que me interessa. O universal funda-se, pois, na exceção. A isso que o senso comum vislumbra no dito "a exceção confirma a regra” podemos acrescentar: o singular exige o universal. A conseqüência desse raciocínio é que:

"Lacan inverte a hierarquia em vigor na oposição universal particular, e ele o faz colocando o acento na dimensão declarativa da lógica (...) A pedra de toque da lógica será para ele o traço particular sobre o qual se apóia a classe universal que se constitui a partir dele." (CATHELINEAU, 1998, p.267, tradução livre).

Essa interpretação permitirá a Lacan retomar o conceito de Bejahung e Verneinung, mostrando a produtividade do quadrante de Peirce para pensar a função do Nomedo-Pai. Por um lado, o nome enquanto o universal, o nome enquanto função nomeadora, o pai enquanto registro do escrito, por outro lado, a existência de um, enquanto função de dar existência, singularidade, o pai enquanto registro da palavra.

Em um primeiro tempo, o pai, como nome, foi acolhido, reconhecido; agora, o pai como nome é confirmado em uma existência particular, o "existe um que não é vertical”, o "ao menos-um” dá existência ao que era um universal sem existência. O juízo de atribuição, “todo traço é vertical”, é um enunciado. Ao acolhimento inicial do enunciado, Bejahung, segue-se uma Verneinung, existe um que não é. O que confirma que o traço existe. O traço existe porque alguém enuncia que ao menos um não é vertical. O enunciado "todo o traço é vertical” ficava ao nível do universal, estava apenas escrito, estava na dimensão do juízo de atribuição, mas não na dimensão do juízo de existência.

Se a atribuição universal não tem, para se manter, necessidade da existência de nenhum de seus atributos, será como atribuição de existência que a particular negativa virá. E se ela é particular, por que, além disso, precisa ser negativa? Essa é a produtividade da função da contradição, uma não vai sem a outra. Dada a universal afirmativa, preciso da particular negativa. Preciso da contraditória para dar existência à atribuição universal afirmava, o traço. Diferentemente de duas proposições contrárias, em que, se uma é falsa, a outra poderá também ser falsa, no caso das contraditórias, se uma é verdadeira, sabe-se que a outra é falsa. Assim, a afirmação da verdade de uma "é acompanhada” da afirmação da negação da outra.

Estamos já em condições de observar o que pode ser chamado de apropriação da Lógica para a produção de uma lógica psicanalítica. Lacan opera com o conceito lógico de contradição para produzir logicamente o conceito psicanalítico de Nome-do-Pai. 
No Seminário O ato analítico, Lacan (1967-1968/2003) retoma a interpretação do quadrante de Peirce, destacando a questão da universalidade. O estatuto da universalidade instaura-se, afirma Lacan, na bipartição superior do quadrante, na reunião dos quadrantes 1 , aquele onde todos os traços são verticais, e 4, aquele onde não há traço, porque o enunciado do universal que diz “todos os traços são verticais” só se sustenta legitimamente nessa reunião. Ao nível do quadrante vazio, é também certo que só há traços verticais, pois onde não há verticais, não há traços. Tal é a definição válida de sujeito enquanto que, sob toda enunciação predicativa, é isso que somente é representado por um significante para outro significante. É pela ausência de traços que se determina o lugar do sujeito, pois, lá onde há traços verticais ou não verticais, existe uma forma de dissimulação, pela presença ou ausência do predicado vertical.

Lacan encontrou, na lógica moderna, a concepção de função e os quantificadores: todo, não todo, algum, pelo menos um. Assim, foi possível articular a representação de sujeito enquanto traço com a concepção de função. Lacan ainda estabelece uma relação com a definição do significante representando um sujeito para outro significante.

Lacan (1971/1996) no Seminário De um discurso que não seria do semblante, retoma a diferença entre um registro escrito e um exercício da palavra (enunciação), ambos constituindo o sujeito dividido pela linguagem. Lacan vai chamar de função do significante mestre, $S_{1}$, essa função da universal afirmativa. Algo se enuncia do traço, mesmo que esse traço não exista. Para dar existência a este traço, é preciso negá-lo, mas essa negação é aquela do reconhecimento simbólico, a negação da Verneinung, que supõe a Bejahung. Esse traço foi acolhido para que possa ser negado. “Ao menos um” não é isso que afirmas, mas, isso que afirmas é acolhido.

A universal afirmativa é puro enunciado de discurso. Mas o que se passa, diz Lacan, quando, dessa lógica aristotélica, passamos à sua transposição na lógica matemática, a dos quantificadores: "Para todo x F(x)" e “ Existe $x$ (Fx)”. Assim, de todo $\mathrm{x}$ pode-se dizer que ele satisfaz aquilo que está escrito em $\mathrm{F}(\mathrm{x})$. Do mesmo modo, existem x que podem ou não funcionar em $\mathrm{F}(\mathrm{x})$. Lacan quer mostrar que é ao redor do escrito que gira a relação entre a universal e a particular no quadrante de Peirce. A função, F(x) tem o papel do que se inscreve, do escrito. A clivagem consiste em se perceber do não-valor da universal negativa, uma vez que aí, de qualquer x que vocês falem, não se deve escrever $\mathrm{F}(\mathrm{x})$. A universal negativa permite dizer que não se deve escrever isso se vocês falam de um x qualquer. A questão está no que não pode se escrever na função $\mathrm{F}(\mathrm{x})$, a partir do momento em que a função F(x) é, ela mesma, para não se escrever (LACAN, 1971/1996, p.106-107). 


\section{A LÓGICA DO SUJEITO}

Chegamos então à proposição de Lacan de que a negação, enquanto negação lógica, somente pode ser articulada pela escrita. O ato de fala é enunciação cujos efeitos de sentido são desencadeados pela conotação significante produzida pela leitura do que se fala. Mas, uma vez que a escrita é conotação significante, a cada enunciação, o sujeito projeta atrás de si, nachträglich, efeitos de sentido.

Lacan (1961-1962/2003) apresenta, no Seminário A identificação, uma análise do ne expletivo francês. A análise gramatical da negação em francês mostra que, no expletivo em frases como Je crains qu'il ne vienne (Temo que ele venha), produzse uma distinção entre o sujeito do ato de enunciação enquanto tal e o sujeito do enunciado, mesmo quando esse último não estiver designado.

A diferença entre esses dois sujeitos é que o sujeito da enunciação encontra sempre um outro suporte, o suporte significante, que pode ser o ne na forma expletiva francesa, mas que pode ser o pas da negação francesa, mas também o “absolutamente nada” em outras línguas. Lacan mostra que a função da negação, presente nessas formas, destaca "o desaparecimento não acabado, deixando atrás de si as marcas do menor traço ou do traço mais evanescente" (LACAN, 19611962/2003, 17/01/1962, p.122). Para compreender a linguagem é necessário, afirma Lacan:

“Ordená-la por meio do que podemos chamar de uma referência a si mesma, a sua própria estrutura como tal (...) como algo que de alguma maneira não se sustenta com uma gênese puramente utilitária, instrumental, prática, uma gênese psicológica, mas que nos mostra a linguagem como uma ordem, um registro, uma função (...) precisamos vê-la como capaz de funcionar fora de toda consciência por parte do sujeito, e cujo campo somos levados a definir como sendo caracterizado por valores estruturais que lhe são próprios." (LACAN, 1961-1962/2003, 10/01/1962, p.97)

O tema da Verneinung pode, portanto, ser lido a partir da distinção lógica entre juízos de universalidade e existência, para então se produzir uma virada que lança o projeto de uma lógica psicanalítica. Esse projeto é tematizado pelo discurso do Outro antecedendo o sujeito. O Outro como o lugar no qual se produz tudo o que pode se enunciar, quer dizer, o que constitui o tesouro dos significantes. A função lógica do sujeito surge quando se considera a diferença entre sujeito do enunciado e sujeito da enunciação, portanto, somente pode surgir se a escritura for tematizada como tal. O sujeito é a raiz da função de repetição e a escritura é a colocação em ato dessa repetição, que busca repetir o que escapa, a saber, a marca primeira que desliza fora do alcance. Isto é, o que Freud denominou de recalque primitivo (Urverdrängung).

A teoria dos conjuntos e a lógica do sujeito se opõem ao nível da escritura. 
Enquanto na teoria dos conjuntos tudo o que se pode dizer de diferente não se escreve, escreve-se apenas o traço que une os elementos heteróclitos em um conjunto. Por exemplo, o conjunto de animais com asas inclui o cavalo mitológico Pégaso, além das aves. A diferença entre os elementos desse conjunto não interessa para a formação do conjunto, mas apenas as semelhanças. Mas é a diferença que faz com que se repita, sobre esses objetos heteróclitos, o mesmo traço de semelhança, neste caso, presença de asas. Mas se não fosse a diferença entre os objetos, não se repetiria o traço unificante. Assim, o um da diferença, o unário enquanto diferença, é considerado como um contável.

\section{A NEGAÇÃO DA DISJUNÇÃO E A LÓGICA DO SUJEITO}

Um outro percurso de Lacan em relação ao conceito lógico de negação é sua análise do cogito cartesiano. O modelo do que Lacan chama de ‘alienação’ referese a uma escolha impossível entre o ‘eu não penso' e o 'eu não sou’. Ou seja, equivale à disjunção lógica. É a análise deste modelo que permite exibir a negação mais fundamental, a negação que funciona em relação à disjunção tal como designada pelo teorema de De Morgan: 'Não (a e b)' equivale a 'não a ou não b'.

O Teorema de De Morgan (1806-1871) refere-se ao tema das equivalências lógicas. Há duas equivalências lógicas de importância que formulam as correlações entre conjunção, disjunção e negação. Diz-se que dois enunciados são materialmente equivalentes em valor de verdade quando são ambos verdadeiros ou ambos falsos. Sempre que dois enunciados são materialmente equivalentes implicam-se, materialmente, um no outro. Isto é facilmente verificável mediante uma tabela de verdade.

A disjunção p ou q meramente afirma que pelo menos um de seus dois disjuntivos é verdadeiro. Para contradizê-la, não basta afirmar que pelo menos um é falso, mas é preciso afirmar que ambos os disjuntivos são falsos (não p e não q). Eis o teorema de De Morgan: "Não (p e q) equivale a (não p ou não q). Não ( p ou q) equivale a (não p e não q). Afirmar a negação da disjunção p ou q é logicamente equivalente a afirmar a conjunção da negação de p e q" (COPI, 1978, p.253).

A passagem das equivalências lógicas aos condicionais (se p então q) é possível, pois há uma relação entre as tautologias (equivalências lógicas) e os argumentos válidos. A todo argumento, corresponde uma proposição condicional cujo antecedente é a conjunção das premissas do argumento e cujo conseqüente é a sua conclusão. Assim, a qualquer argumento da forma “(Se p então q) dado p então q" corresponde uma proposição condicional da forma “(se p então q) e p então q".

Dado o teorema De Morgan: 'Não (a e b)' equivale a 'não a ou não b', e uma vez que "a” designe o "eu penso" e "b” designe o "eu sou”: Lacan constata que 
“Não (eu penso e eu sou)" equivale a “eu não penso ou eu não sou”. É sobre o primeiro termo da equivalência que Lacan vai poder estabelecer a distinção entre sujeito do enunciado e sujeito da enunciação.

Se, na forma cartesiana, "então eu sou” tem que poder colocar-se entre aspas depois do eu penso, é em primeiro lugar porque a função do terceiro é essencial ao cogito. É com um terceiro que eu argumento, fazendo-o renunciar às vias do saber; até surpreendê-lo em uma virada decisiva, fazendo-o confessar que é necessário que eu (je) seja eu (moi), de tal modo que o “eu sou” que ele me dá não é outra coisa, em definitivo, do que o conjunto vazio, posto que se constitui por não conter nenhum elemento.

O “eu penso” não seria de fato mais do que a operação de esvaziamento do conjunto do "eu sou”. O sujeito não se encontra somente em posição de agente do eu penso, mas em posição de sujeito determinado pelo ato mesmo em questão, o que é expresso na língua latina na diátese média.

Diátese significa disposição, estado, condição, a voz do sujeito no verbo. Conforme Benveniste (1995), se, “na voz ativa, os verbos denotam um processo que se efetua a partir do sujeito e fora dele, na voz média, o verbo indica um processo no qual o sujeito é a sede, ou seja, o sujeito está no interior do processo" (BENVENISTE, 1995, p.187).

Assim, no cogito, é preciso recorrer a um terceiro para garantir que, o que diz no interior do processo, seja atestado de fora do processo. O cogito é, portanto, o lugar onde se inaugura um recurso ao Outro. Esse Outro que não está afetado por uma marca. Assim, a negação do eu penso e eu sou equivalerá a escrever não há Outro. A articulação lógica da estrutura subjetiva provém da análise da função do significante. Se o sujeito começa com um corte, o que não está na origem é o sujeito. Mas, o que não está aí, na origem, “o significante não o designa, o engendra” (LACAN, 1966-1967/2003, 16/11/66, p.9). O que é o recalque originário (Urverdrängung)? Um sujeito emerge como sujeito barrado como vindo de um lugar no qual está supostamente inscrito (Outro) e indo para outro lugar no qual vai se inscrever novamente. Nesse sentido, um significante, o significante da falta, produz um sujeito (sujeito barrado) para outro significante (produzindose, no só-depois, o sentido). O primeiro se torna primeiro desde que o sujeito articula seu discurso. O sujeito barrado é o que representa, para um significante, este significante de onde surge um sentido. O que institui o sujeito é um contável que se esconde (Urverdrängung).

A negação lógica é produtiva para a teoria psicanalítica, pois permite pensar o que não se fecha na complementaridade, mas que se abre para novas significações. Vemos, pois, que a intuição freudiana da Verneinung como constituinte do conteúdo negado abre um caminho para uma lógica do sujeito do inconsciente.

O campo da Lógica e o da lógica psicanalítica articulam-se a partir da lin- 
guagem escrita, do que pode ser lido: proposições lógicas e fala, respectivamente. O que permitiu a Lacan pensar uma lógica psicanalítica foi, primordialmente, a questão da fala como leitura da escrita. A lógica supõe a escrita, seja como articulação em seqüência e ordenação de proposições, seja em tabelas de verdade, seja em funções que se aplicam ou não, exige-se a escrita. Esta, por sua vez, é inaugurada pelo significante. Ou seja, primeiro havia o significante que, ao ser lido, engendrou um significado. Assim, também, no caso do sujeito. Primeiro há o significante no Outro, depois se engendra um sujeito como produção de um significante em relação a outro significante.

Recebido em 15/3/2006. Aprovado em 28/4/2006.

\section{REFERÊNCIASS}

ARISTÓTELES (1985) Organon. Tradução, prefácio e notas de Pinharanda Gomes. Lisboa: Guimarães Editores. Periérmeneias, v. I, p.121-173.

BENVENISTE, E. (1950/1995) “Ativo e médio no verbo”, in Problemas de lingüística geral I. Campinas: Pontes/Editora da Universidade Estadual de Campinas.

(1956/1995) "Observações sobre a função da linguagem na descoberta freudiana”, in Problemas de lingüística geral I. Campinas: Pontes/ Editora da Universidade Estadual de Campinas.

CATHELINEAU, P.-C. (1998) Lacan, lecteur d'Aristote. Paris: Éditions de L'Association Freudienne Internationale.

CIRNE- LIMA, C. (1997) Dialética para principiantes. Porto Alegre: Edipucrs.

COPI, I. M. (1978) Introdução à lógica. São Paulo: Mestre Jou.

FREUD, S. (1990) Obras completas. Buenos Aires: Amorrortu Editores.

(1900) "La interpretación de los sueños", v. IV e V, p.3-747.

(1987) Edição Standard brasileira das obras psicológicas completas de Sigmund Freud. Rio de Janeiro: Imago.

(1910) “A significação antitética das palavras primitivas, v. XI, p.137146.

(1925) “A negativa”, v. XX. p.293-300.

(1972) Studienausgabe. Frankfurt: Fischer.

(1925) “Die Verneinung”, v. III, p.371-377.

FREGE, G. (1918-1919/2002) “A negação. Uma investigação lógica”, in Investigações lógicas. Porto Alegre: EDIPUCRS.

HYPPOLITE, J. (1989) “Comentário falado sobre a Verneinung de Freud”, in Ensaios de psicanálise e filosofia. Rio de Janeiro: Taurus/Timbre.

KNEALE, W. e KNEALE, M. (1962) O desenvolvimento da lógica. Lisboa: Fundação Calouste Gulbenkian.

LACAN, J. (1946/1998) "Formulações sobre a causalidade psíquica”, in Escritos. Rio de Janeiro: Jorge Zahar. 
(1953-1954/1979) O Seminário Livro 1, Os escritos técnicos de Freud. Rio de Janeiro: Jorge Zahar.

(1955-1956/1985) O Seminário Livro 3, As psicoses. Rio de Janeiro: Jorge Zahar.

. (1961-1962/2003) O Seminário livro 9, A identificação. Recife: Centro de Estudos Freudianos de Recife. Publicação não comercial.

. (1966-1967/2003) O Seminário livro 14, La lógica del fantasma. Buenos Aires: EFBA. (Publicação não comercial)

(1967-1968/2003) O Seminário livro 15, O ato analítico. Buenos Aires: EFBA. (Publicação não comercial)

(1971/1996) O Seminário livro 18, De um discurso que não seria do semblante. Recife: Centro de Estudos Freudianos de Recife. (Publicação não comercial)

NUNBERG, H. e FEDERN, E. (org.) (1979) Minutes de la Societé psychanalytique deVienne. Paris: Gallimard.

PARMÊNIDES DE ELÉIA (1978) “Fragmentos”, in Os pré-socráticos: fragmentos, doxografia e comentários. Tradução, seleção de textos e supervisão de José Cavalcante de Souza. São Paulo: Abril Cultural.

PEIRCE, C. S. (1931/1968) “Sobre el álgebra de la lógica”, in Escritos lógicos. Madrid: Alianza Editorial.

TUGENDHAT, E. e WOLF, U. (1997) Propedêutica lógico-semântica. Petrópolis: Vozes.

Marta D'Agord

mdagord@terra.com.br 